\title{
Effect of hydrostatic pressure on eggs of Neocalanus copepods during spawning in the deep-layer
}

\author{
Tomoko Yoshiki ${ }^{1,2, *}$, Tsuneo Ono ${ }^{3}$, Akio Shimizu ${ }^{2}$, Tatsuki Toda ${ }^{2}$ \\ ${ }^{1}$ National Fisheries Research Institute, Fisheries Research Agency, 2-12-4, Fukuura, Kanazawa, Yokohama, \\ Kanagawa 236-8648, Japan \\ ${ }^{2}$ Department of Environmental Engineering for Symbiosis, Faculty of Engineering, Soka University, 1-236, Tangi-cho, \\ Hachioji, Tokyo 192-8577, Japan \\ ${ }^{3}$ Department of Hydrographic Science, Hokkaido National Fisheries Research Institute, 116 Katsurakoi, Kushiro, \\ Hokkaido 085-0802, Japan
}

\begin{abstract}
We examined the effect of hydrostatic pressure on copepod eggs to test the hypothesis that eggs of calanoid copepods can develop, hatch, and be successfully recruited under the environmental pressure at which they are released. To explore this hypothesis, the pressure tolerance of eggs of the deep-sea-spawning copepods Neocalanus cristatus, $N$. plumchrus, and $N$. flemingeri was examined and compared with that of Calanus sinicus, which shows egg hatching success that decreases with increasing pressure. The duration of egg development and the hatching success of Neocalanus copepods were measured at $4^{\circ} \mathrm{C}$ under hydrostatic pressures of 1, 10, 50, and 100 atm. Neither the egg development time nor hatching success rates were affected by pressure. This implies that eggs of Neocalanus spp. are adapted to a wide pressure range even though reproduction occurs in a high-pressure environment. Both Neocalanus spp. and C. sinicus live over wide depth ranges throughout their lifetimes - from the ocean surface to depths of greater than $1000 \mathrm{~m}$ - by undergoing ontogenetic vertical migration. However, during early life stages such as the egg and nauplius stages, C. sinicus is exposed only to a narrow pressure range, from 1 to about $10 \mathrm{~atm}$. In contrast, Neocalanus copepods are exposed to a wide pressure range from deep to surface layers during their early life stages. Therefore, the pressure tolerance of the eggs of calanoid copepods appears to be related to the depth range experienced in the early life stages.
\end{abstract}

KEY WORDS: Hydrostatic pressure $\cdot$ Neocalanus $\cdot$ Egg hatching success $\cdot$ Spawning depth

\section{INTRODUCTION}

Neocalanus cristatus, N. flemingeri, and N. plumchrus are abundant in the subarctic Pacific Ocean and the adjacent Bering, Okhotsk, and Japan Seas (Zenkevitch 1963, Motoda \& Minoda 1974, Kobari \& Ikeda 1999, 2001a,b) and are important prey of pelagic fishes, whales, and sea birds (Nemoto 1963, Fukataki 1967, 1969, Taka et al. 1982, Odate 1994, Hunt et al. 1998, Kobari \& Ikeda 1999, 2001a,b). These 3 species of copepods conduct ontogenetic vertical migration (OVM) from the surface to deep ocean layers, as do most calanoid copepods (Kobari \& Ikeda 1999, 2001a,b,
Tsuda et al. 1999, 2001). However, these Neocalanus copepods have lifestyles unique among those of the grazing copepods in that they do not feed during the adult stage and produce eggs by using stored lipids accumulated at the surface (Miller et al. 1984, Conover 1988, Miller \& Clemons 1988, Kobari \& Ikeda 1999, 2001a,b, Tsuda et al. 1999, Saito \& Tsuda 2000). Their larvae grow in the surface layer until reaching copepodite stage $C V$, at which point they descend to their respective spawning depths, molt into adults, and produce eggs below $500 \mathrm{~m} \mathrm{(N.} \mathrm{cristatus)} \mathrm{or} 250 \mathrm{~m}$ (N. flemingeri and N. plumchrus). Although their biology has been well studied because of their abun- 
dance, the biological significance of spawning at depth as it relates to recruitment is not yet known.

Neocalanus eggs are exposed to a high-pressure environment as a consequence of spawning at deeper depths (e.g. Miller et al. 1984, Miller \& Clemons 1988, Tsuda et al. 1999). However, the effect of hydrostatic pressure on Neocalanus eggs has not been examined. For instance, a previous study of egg development in Neocalanus species (Saito \& Tsuda 2000) did not consider the effect of the hydrostatic pressure experienced by Neocalanus spp. in nature, even though their eggs are released at great depths. The effects of hydrostatic pressure on eggs have been well studied in other deep-sea animals; for example, the pressure tolerance of the eggs of echinoid species is closely related to the vertical distribution of adults (Young \& Tyler 1993, Young et al. 1996, 1997, Tyler \& Young 1998, Tyler et al. 2000).

In contrast, similar studies are rarely performed on copepod eggs, except for those of Calanus sinicus. The egg development time of $C$. sinicus is not significantly affected by pressure changes, whereas the egg hatching success decreases with increased pressure, and abnormal nauplii are observed if eggs hatch under high-pressure conditions (Yoshiki et al. 2006). Although $C$. sinicus experiences a wide variation in pressure during $\mathrm{OVM}$ - from $1 \mathrm{~atm}$ at the surface to more than $100 \mathrm{~atm}$ at a depth of $1000 \mathrm{~m}$-adult females are distributed at the surface and their eggs are released only there (Uye et al. 1990, Shimode et al. 2006). These eggs are therefore considered to be adapted to low-pressure environments (Yoshiki et al. 2006, 2008).

The relationship between spawning depth and tolerance of eggs to pressure leads to the hypothesis that the eggs of calanoid copepods are able to develop, hatch, and be successfully recruited under the environmental pressures at which they are released. This hypothesis can be tested by examining the effects of pressure on the eggs of Neocalanus species, which have a particular spawning depth but experience a wide depth range through OVM.

The migration of Neocalanus from the surface to deep depths before molting and reproduction suggests that the deep ocean environment provides conditions suitable for the hatching and recruitment of eggs and larvae. The purpose of the present study was to examine the effects of deep-ocean pressures on Neocalanus eggs in order to explore the hypothesized relationship between spawning depth and egg hatching success in calanoid copepods, and to evaluate whether previous studies of hatching success of Neocalanus eggs represent a naturally occurring phenomenon. In addition, we consider the biological significance of spawning at depth.

\section{MATERIALS AND METHODS}

Sampling and rearing. Neocalanus cristatus, $N$. flemingeri, and $N$. plumchrus were collected during voyages of RV 'Hokko-maru,' of the Hokkaido National Fisheries Research Institute, in the Oyashio region of the Western Subarctic Pacific in January 2006 and January 2007. Sampling was conducted by vertical hauls of a ring net $(65 \mathrm{~cm}$ diameter) with $330 \mu \mathrm{m}$ mesh fitted with a 21 cod end. Hauls were from a depth of either 1000 or $1500 \mathrm{~m}$ to the surface. The contents of the cod end were diluted with surface seawater, and female Neocalanus copepods were sorted from the sample by using a glass pipette and then transferred into $1 \mathrm{l}$ bottles filled with seawater filtered through $0.7 \mu \mathrm{m}$ glass-fiber filters $\left(\mathrm{GF} / \mathrm{F}\right.$; Whatman $\left.{ }^{\circledR}\right)$. Bottles were kept at approximately $4^{\circ} \mathrm{C}$ in either a cold room or an incubator.

After the samples were returned to the laboratory, females were taxonomically classified under a dissecting microscope. Neocalanus plumchrus and N. flemingeri were individually transferred into $250 \mathrm{ml}$ bottles filled with filtered seawater, whereas $N$. cristatus was individually transferred into 21 bottles. The bottles containing copepod females were kept at $4{ }^{\circ} \mathrm{C}$ in the dark and were checked daily for spawning. When eggs were produced, copepod females were transferred to beakers and eggs were counted under a dissecting microscope. The eggs were then transferred to 12 -well $\mathrm{Nunc}^{\circledR}$ multi-well dishes containing about $5 \mathrm{ml}$ of seawater filtered through $0.7 \mu \mathrm{m} \mathrm{GF} / \mathrm{F}$ (Whatman ${ }^{\circledR}$ ); they were then maintained in a temperature-controlled incubator until the experiments began.

Pressure and temperature experiments. Newly spawned eggs were used for pressure and temperature experiments. Temperature experiments under atmospheric pressure conditions were conducted at 4 temperatures $\left(2,4,6\right.$, or $\left.8^{\circ} \mathrm{C}\right)$ for eggs of Neocalanus plumchrus and $N$. flemingeri, and 4,6 , or $8^{\circ} \mathrm{C}$ for $N$. cristatus. These temperatures were chosen to allow a direct comparison with the data of Saito \& Tsuda (2000). Egg development time and hatching success under $1 \mathrm{~atm}$ were observed, and each experiment was performed 6 or 7 times.

Pressure experiments were conducted at 1, 10, 50, and $100 \mathrm{~atm}$ by using a pressure apparatus developed by Yoshiki et al. (2006). The experimental temperature for these pressure experiments was set at $4^{\circ} \mathrm{C}$, which is nearly the same as the spawning temperature. Between 10 and 35 eggs were used at each pressure for each of the 3 species. Each experiment at a given pressure was performed 4 or 5 times for each of the 3 species; the total number of eggs of each species used for each experimental pressure condition ranged from 66 to $>100$ eggs. 
Eggs were placed into the pressure chamber, which was then pressurized by pumping water into the chamber up to the target pressure (Yoshiki et al. 2006). The pressure was increased gradually during the first 100 min to minimize the shock of the pressure change. The hydrostatic pressure apparatus had windows that made it possible to observe specimens and measure the egg development time in the pressure chamber. The contents of the eggs were video-recorded as described previously (Yoshiki et al. 2006). At the end of the experiment, eggs and larvae were removed from the pressure chamber, and hatched larvae were examined for deformation under a dissecting microscope. Egg development times under the respective pressure conditions were determined by visual observation of the video recordings.

We used 1-way analysis of variance (ANOVA) and ANOVA for randomized complete block design to test for differences in egg development times and egg hatching success between pressure conditions. All statistical analyses were performed using the statistical software Kyplot version 5.0 for Windows (Kyence).

\section{RESULTS}

\section{Egg spawning}

Females of Neocalanus cristatus produced 1 to 153 eggs at intervals of $11.7 \pm 0.6 \mathrm{~d}$ (mean $\pm \mathrm{SE}$; Table 1). The clutch size at earlier spawning periods, with a mean of more than 100 eggs, was much larger than those of later spawning periods, which often had fewer than 10 eggs clutch $^{-1}$. The maximum observed clutch number was 7 , and the maximum fecundity was 410 eggs female ${ }^{-1}$.

Similar reproductive patterns were observed for Neocalanus plumchrus, which produced 9 to 237 eggs at intervals of $6.3 \pm 0.5 \mathrm{~d}$ (Table 1). The maximum clutch number for this species was 8 , and the maximum fecundity was 429 eggs female ${ }^{-1}$. The mean clutch size of $N$. flemingeri was the largest of the 3 species (382 \pm 93.5), and the mean spawning interval was $8.1 \pm 0.8 \mathrm{~d}$. The first 2 clutches were the largest, with clutch sizes decreasing sharply as spawning proceeded. The maximum clutch size observed was 623 eggs female ${ }^{-1}$, and the maximum clutch number was 7 .

\section{Egg development time}

Egg development times relative to the temperature at $1 \mathrm{~atm}$ were fitted to Bělehrádek's function, with the following result (Bělehrádek 1935, 1957; Fig. 1):

$$
\begin{gathered}
D=4593(T+27.08)^{-2.05} \text { for Neocalanus cristatus } \\
D=4593(T+28.92)^{-2.05} \text { for } N \text {. plumchrus } \\
D=3208(T+23.70)^{-2.05} \text { for } N \text {. flemingeri }
\end{gathered}
$$

where $D$ is the development time (d) and $T$ is the temperature $\left({ }^{\circ} \mathrm{C}\right)$. Egg development times significantly decreased with increasing temperature $(p<0.001$ for all 3 species; 1-way ANOVA; Table 2). In addition, there were no significant differences between egg development times at $1 \mathrm{~atm}$ and higher pressures at $4^{\circ} \mathrm{C}$ for the 3 Neocalanus species (Fig. 2, 1-way ANOVA; Table 2)

\section{Hatching success}

The average egg hatching success at 1 atm was $53.7 \pm 6.82 \%$ for Neocalanus cristatus, $50.4 \pm 8.38 \%$ for $N$. plumchrus, and $79.4 \pm 4.69 \%$ for $N$. flemingeri (Table 1). There were no significant differences in egg hatching success of the Neocalanus species examined when exposed to pressures from 1 to $100 \mathrm{~atm}$ (Fig. 3, 1-way ANOVA; Table 2). However, in our experiments, the egg hatching success varied from 0 to $100 \%$

\begin{tabular}{|c|c|c|c|c|c|c|}
\hline & \multicolumn{2}{|c|}{ Spawning interval (d) } & \multicolumn{2}{|c|}{ Clutch size (eggs clutch ${ }^{-1}$ ) } & \multicolumn{2}{|c|}{ Egg hatching success (\%) } \\
\hline & Min.-Max. & Mean $\pm \mathrm{SE}$ & Min.-Max. & Mean \pm SE & Min.-Max. & Mean \pm SE \\
\hline \multicolumn{7}{|l|}{ N. cristatus } \\
\hline Present study & $3-20$ & $11.7 \pm 0.6$ & $1-153$ & $89.5 \pm 21.1$ & $0-100$ & $53.7 \pm 6.82$ \\
\hline Saito \& Tsuda (2000) & $7-20$ & $11.0 \pm 1.5$ & $4-110$ & $76.0 \pm 19.3$ & na & $81 \pm 0.15$ \\
\hline \multicolumn{7}{|l|}{ N. plumchrus } \\
\hline Present study & $2-10$ & $6.3 \pm 0.5$ & $9-237$ & $98.2 \pm 59.5$ & $0-100$ & $50.4 \pm 8.38$ \\
\hline Saito \& Tsuda (2000) & $2-8$ & $5.0 \pm 0.7$ & $1-235$ & na & na & $90 \pm 0.22$ \\
\hline \multicolumn{7}{|l|}{ N. flemingeri } \\
\hline Present study & $6-14$ & $8.1 \pm 0.8$ & $7-623$ & $382 \pm 93.5$ & $10-100$ & $79.4 \pm 4.69$ \\
\hline Saito \& Tsuda (2000) & $3-20$ & $8.2 \pm 2.1$ & na-687 & $443 \pm 133$ & na & $93^{\mathrm{a}}$ \\
\hline${ }^{\mathrm{a}}$ Only 1 clutch examir & ned & & & & & \\
\hline
\end{tabular}

Table 1. Neocalanus spp. Spawning interval, clutch size, and egg hatching success as observed in the present study and previously by Saito \& Tsuda (2000). na: data not available 

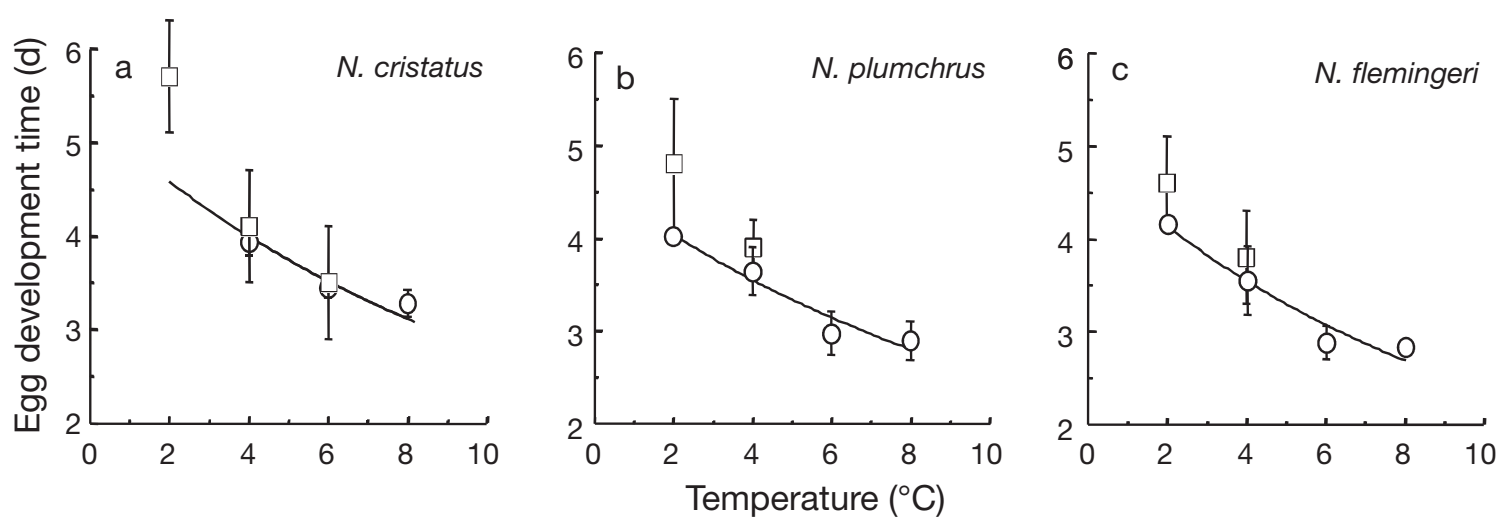

Fig. 1. Neocalanus spp. Average ( \pm SEM) egg development times from the present study (O) and from Saito \& Tsuda (2000) () under atmospheric pressure and different temperatures. Egg development times significantly decreased with increasing temperature (1-way ANOVA, see Table 2)
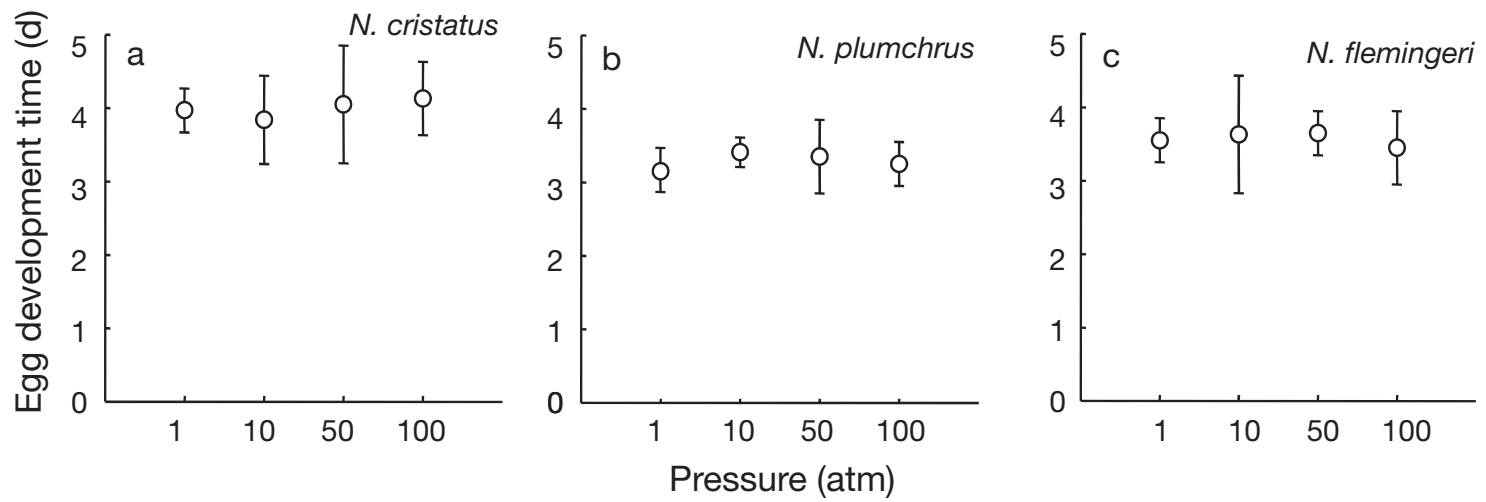

Fig. 2. Neocalanus spp. Average $\left( \pm\right.$ SEM) egg development time under pressures from 1 to 100 atm at $4^{\circ} \mathrm{C}$. Differences in egg development time between pressure conditions were not significant (1-way ANOVA, see Table 2)

among clutches for the 3 Neocalanus copepods, and the average hatching success was low compared to previous results (about 80\%; Saito \& Tsuda 2000). Hence, another experiment was conducted to exclude clutch effects. The egg hatching success data for eggs from the same clutch at pressures of 1, 10, and $100 \mathrm{~atm}$

Table 2. Neocalanus spp. One-way ANOVA of egg development times (EDT) at different temperatures under $1 \mathrm{~atm}$ (see Fig. 1), under pressures from 1 to $100 \mathrm{~atm}$ at $4^{\circ} \mathrm{C}$ (see Fig. 2), and egg hatching success (EHS) under pressures from 1 to $100 \mathrm{~atm}$ (see Fig. 3). Egg development times decreased significantly with increasing temperature, whereas there were no significant differences in egg development times or egg hatching success at differentpressures. Values were considered significant at $p<0.05$

\begin{tabular}{|c|c|c|c|c|c|c|}
\hline \multirow[t]{2}{*}{ Species } & \multicolumn{2}{|c|}{ EDT (temp.) } & \multicolumn{2}{|c|}{ EDT (pressure) } & \multicolumn{2}{|c|}{ EHS (pressure) } \\
\hline & $F$ & $\mathrm{p}$ & $F$ & $\mathrm{p}$ & $F$ & $\mathrm{p}$ \\
\hline N. cristatus & 3.29 & $<0.001$ & 2.76 & 0.070 & 2.33 & 0.887 \\
\hline N. plumchrus & 2.65 & $<<0.0001$ & 2.75 & 0.356 & 2.31 & 0.819 \\
\hline N. flemingeri & 2.68 & $<<0.0001$ & 2.75 & 0.083 & 2.28 & 0.871 \\
\hline
\end{tabular}

were subjected to ANOVA for a randomized complete block design with 5 replicates for each species (Table 3). The sources of variation in this design were pressure and clutch (block). Although the differences among clutches were highly significant $(N$. cristatus and $N$. plumchrus, $\mathrm{p}<0.001$; N. flemingeri, $\mathrm{p}<0.01$ ), the differences among pressure treatments were not significant for any of the 3 species. In other words, the egg hatching success of the species tested did not appear to be affected by hydrostatic pressure.

\section{DISCUSSION}

We compared our results to those of Saito \& Tsuda (2000) for Neocalanus spawning and fecundity (Table 1). Spawning intervals and clutch sizes were almost the same as in the previous observations, and thus the condition of females used in our study was considered comparable to those used by Saito \& Tsuda (2000). 

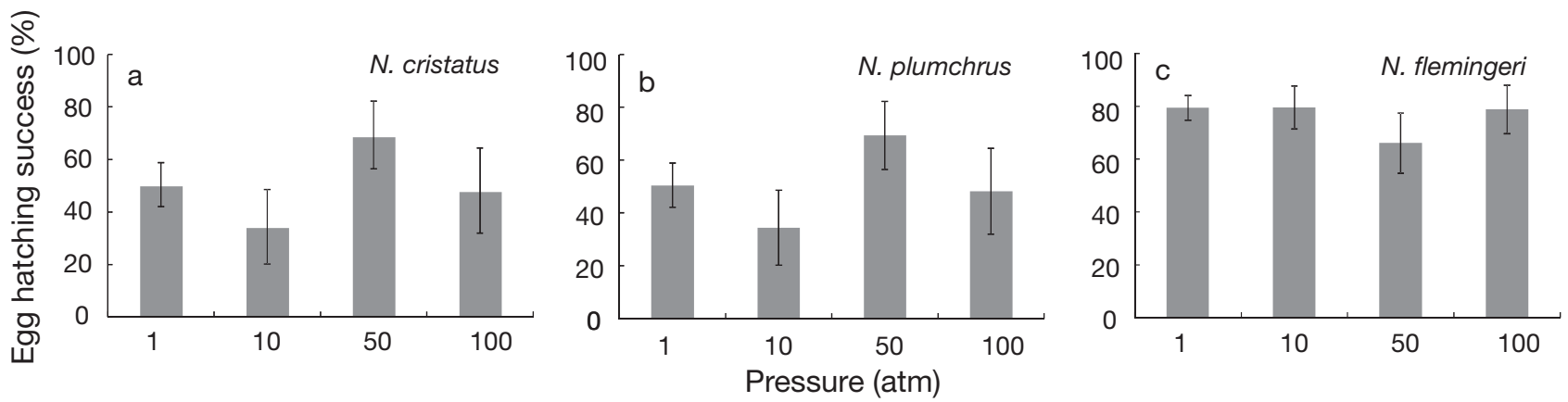

Fig. 3. Neocalanus spp. Average $( \pm$ SEM) egg hatching success under atmospheric and higher pressures. Differences in egg hatching success among pressure conditions were not significant (1-way ANOVA, see Table 2)

Table 3. Neocalanus spp. Analysis of variance for a randomized complete block design of egg hatching success, with ‘block' set at clutch. Values were considered significant at $\mathrm{p}<0.05$

\begin{tabular}{|c|c|c|c|c|c|c|c|c|c|c|c|c|c|}
\hline \multirow[t]{2}{*}{ Source } & \multirow[t]{2}{*}{ df } & \multicolumn{4}{|c|}{ N. cristatus } & \multicolumn{4}{|c|}{ - N. plumchrus } & \multicolumn{4}{|c|}{$-N$. flemingeri } \\
\hline & & SS & MS & $F$ & $\mathrm{p}$ & SS & $\mathrm{MS}$ & $F$ & $\mathrm{p}$ & SS & MS & $F$ & $\mathrm{p}$ \\
\hline Pressure & 2 & 71.37 & 35.68 & 0.186 & 0.834 & 0.2 & 0.10 & 0.0527 & 0.949 & 6.17 & 3.08 & 0.202 & 0.822 \\
\hline Clutch & 4 & 18927.3 & 4731.82 & 24.657 & 0.00015 & 30895.3 & 7723.82 & 4151.476 & $<0.0001$ & 472.07 & 118.02 & 7.710 & 0.00752 \\
\hline Error & 8 & 1535.22 & 191.90 & & & 14.88 & 1.86 & & & 122.45 & 15.31 & & \\
\hline Total & 14 & 20533.9 & & & & 30910.4 & & & & 600.69 & & & \\
\hline
\end{tabular}

The egg development times of the 3 Neocalanus copepods decreased with increasing temperature under atmospheric pressure. In general, development times of crustacean eggs decrease with increasing temperature (e.g. Bělehrádek 1935, 1957). The development times estimated in our study tended to be shorter than those reported by Saito \& Tsuda (2000) at temperatures as low as 2 and $4^{\circ} \mathrm{C}$ (Fig. 1). McLaren et al. (1989) found that the development times of eggs of 4 Pseudocalanus species were related to the size of the eggs, and that this relationship also existed within a species at different geographical locations. Also, egg development times of the calanoid copepod Acartia tonsa are related to the temperature experienced by the females (Hansen et al. 2010). Although it is impossible to know the detailed temperature history of Neocalanus copepods in the field, it is possible that the populations sampled for the present study were exposed to a different range of temperatures than those collected by Saito \& Tsuda (2000).

Under conditions of varying pressure from 1 to $100 \mathrm{~atm}$, the egg development times and hatching success of Neocalanus cristatus, $N$. flemingeri, and $N$. plumchrus were not significantly different (Figs. $2 \& 3$ ). No abnormal hatched nauplii were observed, and the nauplii swam normally under all pressure conditions. These results indicate that neither the egg development time nor the egg hatching success of the 3 Neocalanus species tested was affected by the hydrostatic pressure.
We previously examined the effects of hydrostatic pressure on the egg development time and hatching success of the calanoid copepod Calanus sinicus (Yoshiki et al. 2006). Although egg development time was not influenced by hydrostatic pressure, the egg hatching success rate decreased with increasing pressure. Unhatched eggs of $C$. sinicus were still alive after being removed from the pressure chamber after exposure to elevated pressure, and they subsequently died without hatching even though nauplii had formed in the eggs. Also, even when eggs hatched under highpressure conditions, most nauplii showed abnormalities (Yoshiki et al. 2006, 2008).

The effects of hydrostatic pressure on egg development have been reported in a number of marine animals. For example, the embryonic cleavage rates of Antarctic krill Euphausia superba and shallow-water Mediterranean echinoid species vary under different pressure conditions (George 1984, George \& Stromberg 1985, Young et al. 1997). Embryos of the echinoid species cleaved slowly or did not develop under pressures higher than those at their habitat depths (Young et al. 1997). This suggests that egg development time unaffected by hydrostatic pressure is one of the defining characteristics of calanoid copepods compared to other taxa.

Considerable variation in egg hatching success was observed among clutches (from 0 to $100 \%$ ), although the mean hatching success was not significantly different between the species examined. The results of 

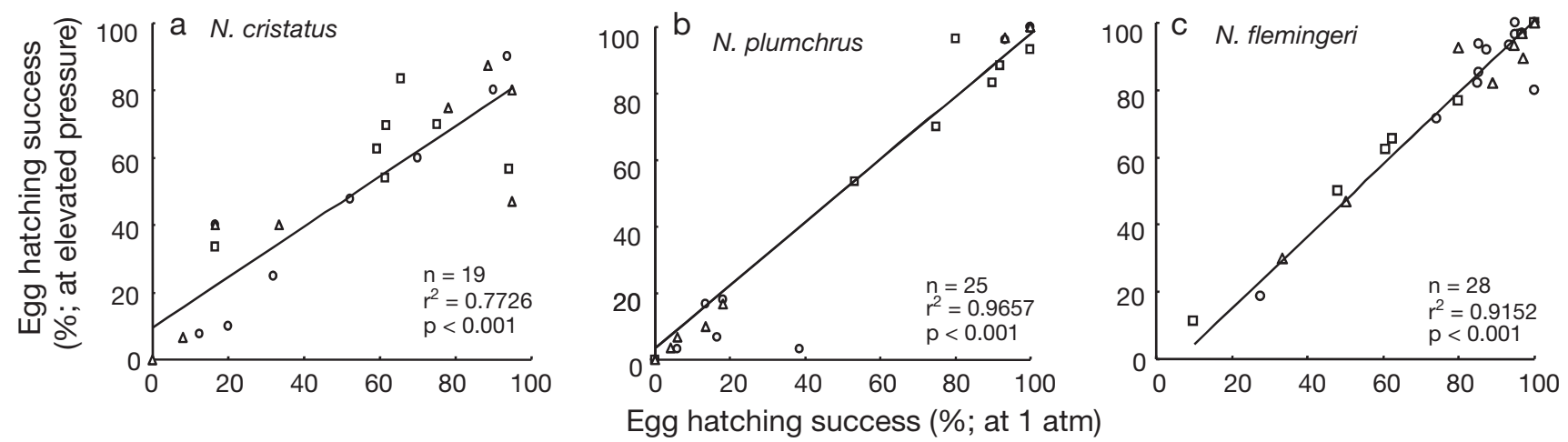

Fig. 4. Neocalanus spp. Egg hatching success under high-pressure conditions of $10 \mathrm{~atm}(\mathrm{O}), 50 \mathrm{~atm}(\square)$, and $100 \mathrm{~atm}(\Delta)$ compared to hatching success of the same clutches at atmospheric pressure. Fitted lines show the correlation between hatching success at higher pressures and at $1 \mathrm{~atm}$ using eggs from the same clutch

ANOVA for a randomized complete block design indicate that egg hatching success was largely influenced by the properties of the individual clutches (Table 3). Taken together, these results indicate that the egg hatching success rates of Neocalanus copepods are not influenced by hydrostatic pressure.

There was a significant positive correlation between the egg hatching success at 1 atm and the hatching success of eggs from the same clutch at higher pressures (10, 50, and $100 \mathrm{~atm}$; Fig. 4). These results reinforce previous laboratory studies of Neocalanus species under atmospheric pressure (Saito \& Tsuda 2000) and are important to consider when studying Neocalanus eggs. However, the high variability of egg hatching success may result from variations in physiological status, such as enzyme or lipid content, that affect the survival rate; this should be determined in future studies.

The life cycle depth ranges of Calanus sinicus and Neocalanus spp. are very different (Fig. 5). Adult $C$. sinicus females are distributed in the surface layer, and the eggs and nauplii are exposed only to a narrow pressure range of 1 to $10 \mathrm{~atm}$ (Uye et al. 1990). In contrast, Neocalanus species are distributed in the deep layer as adults and are exposed to large pressure differences ranging from those in the deep spawning depths to those in shallow waters at the ocean surface in the early life stages (Miller et al. 1984, Mackas et al. 1998, Kobari \& Ikeda 1999, 2001a,b). Thus, the vertical distribution of early life and adult stages differs between $C$. sinicus and Neocalanus spp., even though they both experience depth changes of greater than $1000 \mathrm{~m}$ throughout the course of OVM. The pressure tolerance displayed by copepod eggs may be related to the depth range experienced in the early life stages of the individual species. The present data do not support the hypothesis that eggs of calanoid copepods are able to develop, hatch, and be successfully recruited only under the environmental pressures at which they are released; instead, the data indicate that tolerance of eggs to pressure is unrelated to spawning depth.

Lincoln (1971) reported that the adult stage of the copepod Calanus helgolandicus responds to pressure changes and migrates in the water column. As mentioned previously, there is a decrease in egg hatching success with increasing pressure in the herbivorous $C$. sinicus, which spawns in the surface layer (Yoshiki et al. 2006). Members of the genus Calanus may be able to migrate to depths where the pressure does not adversely affect their eggs when they reproduce during diel vertical migration (DVM). This characteristic in C. sinicus females may lead to successful hatching and recruitment following spawning in the surface layer. In other words, DVM in C. sinicus could be advantageous for egg hatching. From this perspective, the lack of DVM, together with the great spawning depths of female Neocalanus copepods, indicates that deep-ocean environments, and particularly high pressure, are suitable for their reproduction and egg development. However, in the present study, eggs of Neocalanus copepods showed tolerance not only to high pressure but also to pressures as low as $1 \mathrm{~atm}$. Therefore, although female Neocalanus copepods reproduce at deep depths, their eggs do not necessarily require high pressure for development, suggesting that the depth of reproduction serves other functions, such as predation avoidance during the feeble nauplius stage. Neocalanus nauplii grow during the ascent from spawning depths and appear at the surface in the late nauplius or early copepodid stage (Miller et al. 1984, Miller \& Clemons 1988, Miller \& Terazaki 1989, Kobari \& Ikeda 1999, 2001a,b). These larvae comprise a sufficiently large component to compete with other species of copepod nauplii in the surface layer.

The 3 sympatric Neocalanus species examined here appear to avoid competition by subtle differences in the timing of their life cycles and in the strata occupied in the surface layer. For example, N. cristatus spawns 

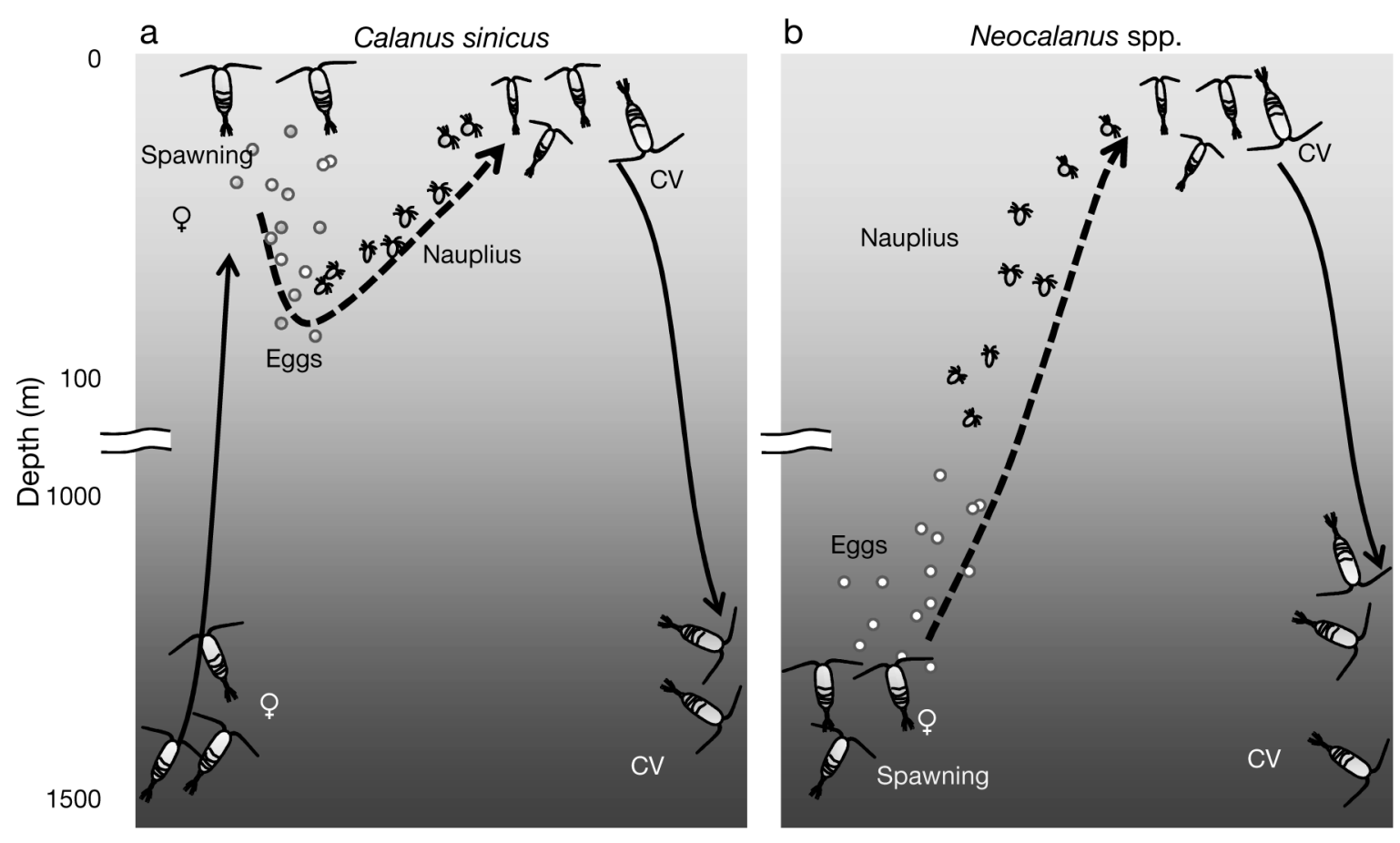

Fig. 5. Calanus sinicus and Neocalanus spp. Depth ranges experienced during early life stages (from egg to nauplius; dotted line)

throughout the year with a peak between October and December (Kobari \& Ikeda 1999), and thus their recruitment period is longer than those of $N$. flemingeri and $N$. plumchrus. In addition, $N$. cristatus inhabits the lower stratum of the surface mixed layer, below that occupied by $N$. flemingeri and N. plumchrus. Although $N$. flemingeri and $N$. plumchrus have similar morphologies and share the upper stratum, they are obviously segregated in distribution depth and the timing of their appearance at the surface (Miller \& Clemons 1988, Mackas et al. 1993, Tsuda et al. 1999, 2001, Kobari \& Ikeda 2001a,b). N. flemingeri uses the surface layer for growth during winter to early spring, whereas N. plumchrus appears in this layer from late spring to summer (Miller et al. 1984, Miller \& Clemons 1988, Miller \& Terazaki 1989, Tsuda et al. 1999, 2001). Also, it appears that the time of first feeding differs between them. We have observed the limit of their growth without food. The last stages reached under starvation conditions were C1 for N. cristatus and N3 for N. plumchrus (T. Yoshiki unpubl. data), i.e. the same as reported by Saito \& Tsuda (2000); we do not have this information for $N$. flemingeri. These are considered to be the last stages of growth using maternal nutrients, and at these stages, the larvae must begin to feed.

The high-pressure adaptation of Neocalanus eggs enables reproduction and recruitment in the deep ocean layers, and it may also allow the hatchlings to reach a large biomass by avoiding competition with other sympatric species. Spending the vulnerable early life stages, including the egg and early nauplius stages, under stable conditions deep in subarctic areas, as opposed to the climatically harsh environment of the surface layer, is considered an important factor allowing Neocalanus spp. to maintain abundant populations.

Our results suggest that the pressure tolerance of the eggs of calanoid copepods is related to the depth range experienced during the early life stages. Future investigations of calanoid copepods, with their unique characteristics of life cycle, distribution depth, and habitat, are necessary to reveal the precise effects mediated by hydrostatic pressure.

Acknowledgements. We thank T. Sugiyama of the Institute of Statistical Mathematics and Soka University and H. Miyaguchi of Soka University for valuable suggestions, which improved this manuscript. We also thank K. Takahashi of the Tohoku National Fisheries Research Institute of the Fisheries Research Agency (Japan) and J. Nishioka of the Institute of Low Temperature Science, Hokkaido University, for helpful comments regarding this manuscript. We are indebted to the captain and crew of RV 'Hokko-maru' of the Hokkaido National Fisheries Research Institute, Fisheries Research Agency, for help in collecting samples.

\section{LITERATURE CITED}

Bělehrádek J (1935) Temperature and living matter. Protoplasma Monogr 8. Borntraeger, Berlin

Bělehrádek J (1957) Physiological aspects of heat and cold. Annu Rev Physiol 19:59-82 
Conover RJ (1988) Comparative life histories in the genera Calanus and Neocalanus in high latitudes of the northern hemisphere. Hydrobiologia 167-168:127-142

Fukataki H (1967) Stomach contents of the pink salmon, Oncorhynchus gorbuscha (Walbaum), in the Japan Sea during spring season of 1965. Bull Jpn Sea Reg Fish Lab $17: 49-66$

Fukataki H (1969) Stomach contents of the pink salmon, Oncorhynchus masou (Brevoort), in the offshore regions of the Japan Sea. Bull Jpn Sea Reg Fish Lab 21:17-34

George RY (1984) Ontogenetic adaptations in growth and respiration of Euphausia superba in relation to temperature and pressure. J Crustac Biol 4:252-262

George RY, Stromberg JO (1985) Development of eggs of Antarctic krill Euphausia superba in relation to pressure. Polar Biol 4:125-133

Hansen BW, Drillet G, Kozmer A, Madsen KV, Pedersen MF, Sørensen TF (2010) Temperature effects on copepod egg hatching: Does acclimatization matter? J Plankton Res 32: 305-315

> Hunt GL Jr, Russell RW, Coyle KO, Weingartner T (1998) Comparative foraging ecology of planktivorous auklets in relation to ocean physics and prey availability. Mar Ecol Prog Ser 167:241-259

Kobari T, Ikeda T (1999) Vertical distribution, population structure and life cycle of Neocalanus cristatus (Crustacea: Copepoda) in the Oyashio region, with notes on its regional variations. Mar Biol 134:683-696

Kobari T, Ikeda T (2001a) Life cycle of Neocalanus flemingeri (Crustacea: Copepoda) in the Oyashio region, western subarctic Pacific, with notes on its regional variations. Mar Ecol Prog Ser 209:243-255

Kobari T, Ikeda T (2001b) Ontogenetic vertical migration and life cycle of Neocalanus plumchrus (Crustacea: Copepoda) in the Oyashio region, with notes on regional variations in body sizes. J Plankton Res 23:287-302

Lincoln RJ (1971) Observations of the effects of changes in hydrostatic pressure and illumination on the behavior of some planktonic crustaceans. J Exp Biol 54:677-688

Mackas DL, Sefton H, Miller CB, Raich A (1993) Vertical habitat partitioning by large calanoid copepods in the oceanic subarctic Pacific during spring. Prog Oceanogr 32:259294

Mackas DL, Goldblatt R, Lewis AG (1998) Interdecadal variation in developmental timing of Neocalanus plumchrus populations at Ocean Station P in the subarctic North Pacific. Can J Fish Aquat Sci 55:1878-1893

McLaren IA, Sevigny JM, Frost BW (1989) Evolutional and ecological significance of genome sizes in the copepod genus Pseudocalanus. Can J Zool 67:565-569

Miller CB, Clemons MJ (1988) Revised life history analysis for large grazing copepods in the subarctic Pacific Ocean. Prog Oceanogr 20:293-313

Miller CB, Terazaki M (1989) Life histories of Neocalanus flemingeri and Neocalanus plumchrus in the Sea of Japan. Bull Plankton Soc Japan 36:27-41

Miller CB, Frost BW, Batchelder HP, Clemons MJ, Conway RE (1984) Life histories of large, grazing copepods in a Subarctic Ocean Gyre: Neocalanus plumchrus, Neocalanus cristatus, and Eucalanus bungii in the Northern Pacific. Prog Oceanogr 13:201-243

Motoda S, Minoda T (1974) Plankton of the Bering Sea. In:
Hood DW, Kelly EJ (eds) Oceanography of the Bering Sea with emphasis on renewable resources. Institute of Marine Science, University of Alaska Fairbanks, Fairbanks, AK, p 207-241

Nemoto T (1963) Some aspects of the distribution of Calanus cristatus and C. plumchrus in the Bering Sea and its neighboring waters, with reference to the feeding of baleen whales. Sci Rep Whales Res Inst Tokyo 17:157-170

Odate K (1994) Zooplankton biomass and its long-term variation in the western North Pacific Ocean. Tohoku Natl Fish Res Inst 56:115-173

Saito H, Tsuda A (2000) Egg production and early development of the subarctic copepods Neocalanus cristatus, N. plumchrus and N. flemingeri. Deep-Sea Res I 47:21412158

Shimode $\mathrm{S}$, Toda T, Kikuchi T (2006) Spatio-temporal changes in diversity and community structure of planktonic copepods in Sagami Bay, Japan. Mar Biol 148:581-597

Taka S, Kitakata M, Wada T (1982) The relations between the saury, Cololabis saira (Brevoort) and the food organisms, especially Calanus plumchrus, in the southeast waters of the Kuril Islands during the summer. Bull Hokkaido Reg Fish Res Lab 47:41-55

Tsuda A, Saito H, Kasai H (1999) Life histories of Neocalanus flemingeri and Neocalanus plumchrus (Calanoida: Copepoda) in the western subarctic Pacific. Mar Biol 135:533544

Tsuda A, Saito H, Kasai H (2001) Life history strategies of subarctic copepods Neocalanus flemingeri and N. plumchrus, especially concerning lipid accumulation patterns. Plankton Biol Ecol 48:52-58

- Tyler PA, Young CM (1998) Temperature and pressure tolerances in dispersal stages of the genus Echinus (Echinodermata: Echinoidea): prerequisites for deep-sea invasion and speciation. Deep-Sea Res II 45:253-277

> Tyler PA, Young CM, Clarke A (2000) Temperature and pressure tolerances of embryos and larvae of the Antarctic sea urchin Sterechinus neumayeri (Echinodermata: Echinoidea): potential for deep-sea invasion from high latitudes. Mar Ecol Prog Ser 192:173-180

- Uye S, Huang C, Onbe T (1990) Ontogenetic diel vertical migration of the planktonic copepod Calanus sinicus in the Inland Sea of Japan. Mar Biol 104:389-396

Yoshiki T, Toda T, Yoshida T, Shimizu A (2006) A new hydrostatic pressure apparatus for studies of marine zooplankton. J Plankton Res 28:563-570

> Yoshiki T, Yamanoha B, Tomohiko K, Shimizu A, Toda T (2008) Hydrostatic pressure-induced apoptosis on nauplii of Calanus sinicus. Mar Biol 156:97-106

> Young CM, Tyler PA (1993) Embryos of the deep-sea echinoid Echinus affinis require high pressure for development. Limnol Oceanogr 38:178-181

> Young CM, Tyler PA, Gage JD (1996) Vertical distribution correlates with pressure tolerances of early embryos in the deep-sea asteroid Plutonaster bifrons. J Mar Biol Assoc UK 76:749-757

Young CM, Tyler PA, Fenaux L (1997) Potential for deep sea invasion by Mediterranean shallow water echinoids: pressure and temperature as stage-specific dispersal barriers. Mar Ecol Prog Ser 154:197-209

Zenkevitch L (ed) (1963) Biology of the seas of the U.S.S.R. George Allen \& Unwin, London

Submitted: February 19, 2010; Accepted: February 17, 2011 Proofs received from author(s): May 6, 2011 